\title{
El debido proceso y la cadena de custodia frente a las pruebas judiciales presentadas por el auditor forense*
}

\author{
Rodrigo Alberto Plazas Estepas \\ Ludivia Hernández Aros \\ Mario Heimer Flórez Guzmán
}

Recibido: 6 de octubre de 2016 • Aprobado: 15 de noviembre de 2016

\section{Resumen}

El presente artículo tiene como objetivo relatar el proceso que se debe seguir en la cadena de custodia tal como lo expresa la Ley 906 de 2004 (Congreso de la República de Colombia, 2004), específicamente en un encargo de auditoría forense, lo anterior en razón a que todo proceso de auditoría debe ajustarse a las normas internacionales de auditoría (NIAS), contenidas en el Decreto 2420 de diciembre de 2015 (Presidencia de la República de Colombia, 2015), las cuales garantizan

"Artículo derivado de proyecto de investigación "aseguramiento continuo de la información financiera mediante tableros de control”, asociado al Grupo PLANAUDI, adscrito al Centro de Investigaciones del Programa de Contaduría Pública de la Universidad Cooperativa de Colombia, sede Ibagué, financiado por CONADI. DOI: http://dx.doi.org/10.15332/s1900-0448.2016.0045.02

" Candidato a doctor en Derecho por la Universidad de Buenos Aires (UBA). Magister en Derecho de la Universidad Sergio Arboleda. Director de Investigaciones de la Corporación Universitaria Republicana (Bogotá, Colombia). Correo electrónico: rodrigoplazas@urepublicana.edu.co

**a Profesora e investigadora de la Facultad de Contaduría Pública de la Universidad Cooperativa de Colombia, sede Ibagué (Colombia). Integrante del grupo de investigación PLANAUDI. Estudiante de maestría en Auditoría y Gestión Empresarial de la Universidad UNINI (Puerto Rico). Especialista en Revisoría Fiscal y Control de Gestión de la Universidad Cooperativa de Colombia. Correo electrónico: Ludivia.hernandez@campusucc.edu.co

" Alumno de doctorado (formación académica), profesor investigador de tiempo completo de la Universidad Cooperativa de Colombia, sede Ibagué (Colombia). Integrante del grupo de investigación PLANAUDI del programa de Contaduría Pública de la Universidad Cooperativa de Colombia. Correo electrónico: mario.florez@campusucc.edu.co 
eficiencia y eficacia en dicho encargo. De igual forma, dentro de la ejecución de la auditoría forense se debe tener en cuenta la recolección de prueba pericial amplia y suficiente, su grado de legalidad, su autenticidad y el grado actual de aceptación científica, así como la importancia que tiene el debido proceso en la cadena de custodia, lo que permitirá elevar el nivel de confianza de estas en un proceso judicial.

Palabras clave: Auditoría forense, debido proceso, cadena de custodia, prueba judicial, NIAS.

\title{
The due PRocess and THE CUSTOdy ChaIN Against THE JUDICIAL EVIDENCE REPORTED BY THE FORENSIC AUDITOR
}

\begin{abstract}
This paper has as main objective describe the process to be followed in the chain of custody as is mentioned in the law 906 of 2004 (Colombian Republic congress, 2004), specifically in topics related to forensic audit, the mentioned before taking into account that all audit processes must to be adjust to the International Audit Standards (IAS), stated in the decree 2420 of December of 2015 (Presidency of the Republic of Colombia, 2015), which guarantee efficiency and effectiveness in such process. In the same way, within the execution of the forensic audit must be take into account the extend and sufficient expert evidence and the actual scientist grade of acceptation, as well as the relevance who has the due process in the custody chain, which will allow get a high confidence level in a judicial process.
\end{abstract}

Keywords: Forensic audit, due process, chain of custody, legal evidence, NIAS.

\section{O DEVIDO PROCESSO E A CADEIA DE CUSTÓDIA PERANTE AS PROVAS JUDICIAIS APRESENTADAS PELO AUDITOR FORENSE}

\section{Resumo}

Este artigo tem como objetivo relatar o processo que se deve seguir na cadeia de custódia como o estabelece a Lei 906 de 2004 (Congresso da República da Colômbia, 2004), especificamente em um encargo de auditoria forense, todo isso porque todo processo de auditoria deve-se ajustar a normas internacionais de auditoria (NIAS) apresentadas no Decreto 2420 de dezembro de 2015 (Presidência da República 
da Colômbia, 2015) as quais garantem e eficiência e eficácia em este encargo. Da mesma forma, no relacionado com a execução da auditoria forense se deve levar em consideração a colheita da prova pericial ampla e suficiente, seu grão de legalidade, sua autenticidade e o grau atual de aceitação cientifica, assim como a importância que tem o devido processo na cadeia de custódia, o qual permitirá elevar o nível de confiança de estas em um processo judicial.

Palavras-chave: Auditoria forense, devido processo, cadeia de custódia, prova judicial, NIAS.

\section{Introducción}

Uno de los campos de acción del contador público se da cuando se requieren sus servicios profesionales para actuar como auditor forense ${ }^{1}$. Y esta experticia-por parte del contador- en el encargo de auditoría forense es importante en el proceso de recolección de una evidencia amplia, suficiente y competente, que sirva como medio de prueba para los diferentes grupos de interés (Stakeholders) y en el caso específico en el que se presuman conductas delictivas que hayan afectado el patrimonio económico de una persona natural o jurídica y, si es el caso en su encargo, que las pruebas obtenidas pueden ayudar a establecer la responsabilidad penal en un proceso judicial.

Concomitante con lo anterior, algunas modalidades de fraude que el auditor forense identifica son fraudes a los estados financieros, malversación de bienes, fraude en sobornos, en proceso de quiebras e insolvencias y fraudes de impuestos, entre otros ${ }^{2}$. Bajo este referente, cada una de las actividades que desarrollan en la

${ }^{1} \mathrm{Al}$ respecto, Singleton, Bologna y Lindquist (2006) se refieren a los contadores forenses como aquellos profesionales contables que ayudan a encontrar la evidencia del fraude; y es esta particularidad que sus fuertes conocimientos en el proceso contable van acompañados con conocimientos sólidos de auditoría, valoración de riesgos y control. De igual forma Rodríguez (2009) afirma que el auditor forense debe demostrar conocimiento del ambiente legal, necesario para su trabajo como litigante, y tener una serie de habilidades para la eficiente ejecución de su labor, como la comunicación, habilidades de detective y de litigante audaz.

${ }^{2}$ Leal, Rodríguez y González (2010) definen las modalidades de fraudes así: a) fraudes con los estados financieros, los cuales tipifican los registros del proceso contable que no sean soportes de la contabilidad y que, a su vez, no cumplan lo reglamentado por el Código de Comercio y el Estatuto Tributario; por otro lado, también se incluye la manipulación contable; b) modalidad en malversación de bienes: se puede cumplir el desfalco de ingresos, robo de activos o bienes o servicios pagados que no 
auditoría forense - por parte del auditor forense- es producto de la planeación de su trabajo, que implica el conocimiento del negocio, del sector y de las variables endógenas y exógenas propias del caso a estudiar³

En el ámbito empresarial, la auditoría forense juega un gran papel en el plano mundial, originado por los múltiples escándalos financieros como los ocurridos en EE. UU., específicamente en la empresa de energía Enron y en WorldCom; en México, con HSBC y el lavado del dinero; en Italia, con el caso Parmalat; y en Colombia, con la Sociedad DMG, el Grupo Holding S. A., la DIAN, SaludCoop, entre otros. Por lo anterior, se origina la necesidad de la detección temprana del fraude en los estados financieros, con el empleo de técnicas y herramientas específicas -tradicionales y especializadas-, que ayuden a combatir el dolo organizacional y que actúen en concordancia con los procesos judiciales.

La auditoría forense, dentro de su estudio previo, reconoce que toda empresa está expuesta al fraude; por lo tanto, al reconocer estos actos delictivos en el interior de una organización, se obtiene toda clase de evidencias útiles al momento de rendir su informe o en caso de que se requiera preparar un dictamen pericial para los tribunales.

\section{Prueba pericial}

El Código de Procedimiento Civil en Colombia - Decreto 1400 de 1970 (Presidencia de la República de Colombia, 1970) expone que, para proferir una

se han recibido; c) fraudes en sobornos, que se tipifican cuando se aceptan obsequios monetarios o en especie para que se influya positiva o negativamente en una decisión; d) fraude en procesos de quiebras e insolvencias, los cuales se presentan cuando, sin cumplir los requisitos de ley, se declara insolvente a una persona o se acomodan los resultados de acuerdos concordatarios; e) fraudes en impuestos, cometidos para favorecer interés particular y cancelar menos impuestos.

${ }^{3}$ Ramírez y Reina (2013) identifican la planeación como primordial para el desarrollo del encargo de auditoría forense, iniciando por entender el negocio NIA 315. Identificar riesgos e indicadores de fraude. NIA 320. En cuanto al personal, el auditor forense deberá identificar comportamientos inusuales comerciales y financiero. Su análisis deberá incluir incluye los síntomas, a saber: baja moral, alta rotación de los directivos y poco seguimiento y control sobre las metas. En cuanto a los aspectos estructurales, es importante indagar y registrar los sitios remotos mal supervisados y la búsqueda de resultados a cualquier costo. En lo referente al aspecto cultural, es necesario verificar que no existan presiones de sus superiores y del temor a perder el empleo. Ya en la evaluación del control interno se indagará sobre factores de seguridad que brinde el control interno de la entidad; la evaluación se deberá organizar y administrar de forma apropiada. Con respecto al alcance, este se determinará mediante un análisis del control interno organizacional que permitirá detectar errores significativos. Por otro lado, el auditor forense deberá desarrollar estrategias o tácticas en auditoría que le permitan identificar la materialidad (transacciones, hechos significativos) y la relación de cada hecho o indicio que pueda ser objeto de investigación. 
decisión de fondo, la regla general consiste en que esta debe fundarse en pruebas regular y oportunamente allegadas al proceso $(174, \mathrm{CPC})$; en el mismo sentido, la Constitución Política de Colombia (CPC), en su artículo $29^{4}$ aclara que las pruebas que se obtengan con violación del debido proceso, serán nulas de pleno derecho ${ }^{5}$ (Congreso de la República de Colombia, 2012).

De acuerdo con lo anterior, rigen dos principios: 1) la preclusión de la oportunidad, que señala que el medio probatorio debe ser allegado e incorporado en los términos procesales, so pena de ser rechazado por extemporáneo; y 2) el debido proceso, que exige el cumplimiento de las formalidades propias del ordenamiento, el cual se considera de orden público y de obligatorio cumplimiento. Estos dos principios darán legalidad a la prueba ${ }^{6}$ desde el concepto de amplia y suficiente ${ }^{7}$.

Ahora bien, respecto a los documentos, se debe tener en cuenta que, como lo indica Llunch (2012, p. 53), debe tenerse presente la facultad de impugnar la autenticidad de los documentos presentados de adverso (art. 427.1 LEC), impugnación que se circunscribe a la autenticidad del documento, entendida como pertenencia a su autor; tales documentos se constituyen como prueba pericial, si son procedentes para un proceso judicial, cuando se verifiquen o valoren hechos que interesen al proceso, y cuando requieran especiales conocimientos especializados (Caro, Hernández, Gallego \& Flórez, 2015)

${ }^{4}$ CPC.Artículo 29. El debido proceso se aplicará a toda clase de actuaciones judiciales y administrativas. Nadie podrá ser juzgado sino conforme a leyes preexistentes al acto que se le imputa, ante juez o tribunal competente y con observancia de la plenitud de las formas propias de cada juicio. En materia penal, la ley permisiva o favorable, aun cuando sea posterior, se aplicará de preferencia a la restrictiva o desfavorable (...). Es nula, de pleno derecho, la prueba obtenida con violación del debido proceso.

${ }^{5}$ Artículo 164. Necesidad de la prueba. Toda decisión judicial debe fundarse en las pruebas regular y oportunamente allegadas al proceso. Las pruebas obtenidas con violación del debido proceso son nulas de pleno derecho.

${ }^{6}$ En este sentido, se conocen como medios de prueba aptos para ser incorporados a un proceso la declaración de parte, el juramento, el testimonio de terceros, la inspección judicial, los documentos, los indicios, el dictamen pericial y cualesquiera otros medios que sean útiles para la formación del convencimiento del juez (175, CPC; 165 , CGP), siempre preservando los principios y las garantías constitucionales, so pena de ser excluido del proceso. Lluch (2012, p. 53) argumenta que "las fuentes de prueba son conceptos preexistentes al proceso (la parte; el testigo; el documento; el lugar, objeto o persona que ha ser examinado; el conocimiento técnico del perito) y los medios de prueba son conceptos que existen en y para el proceso (el interrogatorio de las partes o de testigos, la prueba documental, el reconocimiento judicial, el dictamen de peritos)".

${ }^{7}$ Al respecto, Cortés (2011,p. 4) ha establecido que "las exigencias de la evolución y transformación social requieren de un replanteamiento concreto y unificado, que permita que los postulados constitucionales sean una realidad frente a la cual los ciudadanos de cada nación vean garantizados su dignidad y sus derechos fundamentales". 
En conclusión, la prueba pericial, para que sea tenida en cuenta en el proceso judicial, debe revestirse de legalidad, cumpliendo con todos los requisitos exigidos por la ley colombiana, así como también ser producto de un proceso de auditoría hecho por un perito designado por el juez o de quien sea la competencia; además, la prueba debe ser amplia y suficiente, para que aporte significativamente al proceso judicial.

La palabra perito viene del latín peritus, que significa "experto en una determinada materia, ya sea artística, técnica o científica"; por lo tanto, la figura del perito resulta relevante en el ámbito judicial para la resolución de conflictos en aquellas materias extrajurídicas que escapan a la comprensión del juez, o bien, porque al tener ese conocimiento, esa comprensión, es necesaria su incorporación al proceso para que se dé un contradictorio adecuado, sin que en ningún caso el juez pueda suplirlo -necesidad de la prueba y prohibición de aplicar su conocimiento privado sobre los hechos-.

Ahora bien, la elección del perito será fundamental en la obtención de la prueba pericial de parte, uno que ofrezca las garantías de solvencia profesional, a quien deberán presentarse los extremos concretos de la prueba pericial, así como su eventual intervención en el acto del juicio. En el derecho privado, tradicionalmente se acude a la lista de auxiliares de la justicia, lo cual no es óbice para que las partes puedan asesorarse de expertos en la materia, razón por la cual, en ciertas ocasiones, el concepto de perito se diferencia del concepto de testigo técnico, lo cual tiene consecuencias importantes en la práctica, sobre todo frente a la ritualidad y la manera de darse la contradicción del medio probatorio.

Así las cosas, la prueba pericial solo será procedente cuando sea necesaria la verificación o la valoración de los hechos que interesen al proceso y que requieran especiales conocimientos científicos, técnicos o artísticos (233, CPC; 266, CGP), o especializados. Y en cuanto al ámbito penal, por expresa disposición, al perito le serán aplicables, en lo que corresponda, las reglas del testimonio (405 Ley 906 de 2004), en razón a que el perito debe entrar a sustentar la razón de ser de su dictamen, cuyo contenido puede ser científico, técnico, artístico o especializado, según la materia que se trate, lo cual es aplicable a las demás áreas del derecho cuando así se pida8.

${ }^{8}$ Ahora bien, como características fundamentales de este medio probatorio, Campo Izquierdo (2011) explica que encontramos que la pericia es una actividad procesal probatoria que tiene lugar en el periodo de prueba del proceso y cuyo fin es facilitar la percepción y la apreciación de los hechos 
Para los efectos del presente estudio, cuando el contador público preste sus servicios de apoyo en litigios en los cuales su actuación se lleve a cabo en el campo de auditoría, el Decreto $0302^{\circ}$, en su ítem 290.207, explica que se acude a que "los servicios de apoyo en litigios pueden incluir actividades como la actuación en calidad de perito, el cálculo de daños estimados o de otras cantidades, que pueden resultar a cobrar o a pagar como resultado del litigio o de otra disputa legal y la asistencia en relación con la gestión y obtención de documentos. La realización de estos servicios puede originar una amenaza de autorrevisión o de abogacía"10.

De igual forma, se hace importante para cualquier juicio conocer la legalidad de la prueba. Según la Constitución Política de 1991, Colombia es un Estado social democrático de derecho (Art. 1), por lo que "los jueces en sus providencias solo están sometidos al imperio de la ley" (Art. 230); estas normas de carácter constitucional marcan el camino que los contadores deben seguir, esto es, el respeto por la legalidad para el ejercicio de sus funciones. Lo anterior tiene especial trascendencia si se tiene en cuenta que al dar fe de las actuaciones con su firma se asimilan a funcionaros, lo cual hace presumir que sus actos "se ajustan a los requisitos legales".

No obstante, esa presunción admite prueba en contrario, razón por la cual, cuando se demuestre o en su defecto se presuma que el contador obró contra la ley, se verá expuesto a un triple efecto: primero, a las sanciones penales por las conductas punibles que cometa; segundo, a las sanciones civiles por los perjuicios que pueda ocasionar con sus actos; y tercero, a las sanciones disciplinarias, por actuar conforme a la Ley 43 de $1990^{11}$. Por lo anterior, para evitar las sanciones a

concretos objeto del debate; no obstante, como se mencionó, las partes pueden asesorarse de expertos en el área del conocimiento a nivel extraprocesal para ser presentado con posterioridad al proceso, siendo el elemento fundamental de este medio la aportación de ese conocimiento extrajurídico de que adolece el juez; pese a que, de manera general, la prueba pericial se presenta por escrito, también puede ser personal, en la medida en que el perito puede ser llamado para que, al igual que la prueba testimonial, rinda un concepto sobre los hechos que se indagan y es preciso aportar al proceso.

${ }^{9}$ Decreto 0302, compilado en el decreto 2420 de diciembre de 2015

${ }^{10}$ Se hace referencia a las controversias de carácter contable. Según la Ley 43 de 1990, por medio de la cual se adicionó la Ley 145 de 1960, reglamentaria de la profesión de contador público, se requiere ser contador para actuar como perito, puesto que la complejidad de las relaciones que rodean hoy en día al contador hace necesaria su presencia en casi todos los aspectos de la vida, pues, por ley, el contador está facultado para dar "fe pública de hechos propios del ámbito de su profesión" (Art. 1). En este sentido, toda su actividad puede ser objeto de controversia cuando se ponga en tela de juicio su "fe" impuesta a su actuación, esto es, que "el acto se ajusta a los requisitos legales, lo mismo que a los estatutarios en caso de personas jurídicas” (Art. 10).

${ }^{11}$ Parágrafo. Los contadores públicos, cuando otorguen fe pública en materia contable, se asimilarán a funcionarios para efectos de las sanciones penales por los delitos que cometieren en el ejercicio de 
que haya lugar, se debe tener presente la máxima general que reza: "la ignorancia de la ley no sirve de excusa” (art 10).

La prueba ha sido definida como "todo lo que sirve para darnos la certeza acerca de la verdad de una proposición” ${ }^{12}$.

\section{El debido proceso y la cadena de custodia}

A nivel general, es deber de toda persona (particular o servidor público) denunciar ante la Fiscalía la comisión de un hecho que pueda constituir un delito; y es deber de la Fiscalía investigar, perseguir y acusar a los presuntos responsables de su comisión; en desarrollo de esta actividad, ordenará los registros, allanamientos, incautaciones e interceptaciones de comunicaciones a que haya lugar.

Es así como la policía judicial, en desarrollo de las órdenes de trabajo impartidas por la Fiscalía, se trasladará al lugar de los hechos con el fin de examinar de manera minuciosa, completa y metódica todos los elementos materiales y personales probatorios que tiendan a demostrar la realidad del hecho y a señalar al o a los autores y partícipes del hecho; a descubrir, asegurar, identificar, recoger, embalar y custodiar los elementos, de acuerdo con los procedimientos técnicos establecidos en los manuales de criminalística.

\subsection{La cadena de custodia}

Por lo anterior el auditor forense deberá tener en cuenta los elementos descubiertos y utilizados en sede de audiencia (preliminar o de juzgamiento), así como los manuales de criminalística, los cuales deberán ser acordes al sistema de fuentes del bloque de constitucionalidad que garantiza los derechos fundamentales, dentro de los cuales encontramos el Pacto de Derechos Civiles y Políticos (PIDCP) y la Convención Americana de Derechos Humanos (CADH), entre otros, que concretan el alcance de las garantías previstas en la Constitución y por la ley.

las actividades propias de su profesión, sin perjuicio de las responsabilidades de orden civil que hubiere lugar conforme a las leyes.

${ }^{12}$ Cano, D., Lugo, D., Cano, M., \& Cano, J. E. (2008), definen claramente qué pruebas periciales pueden ser presentadas por el contador público, como la fotografía técnica forense; rastros, manchas, pruebas de caligrafía; videograbación con cámaras ocultas selladas, con programación de tiempo y fecha; audiograbación y verificación de voz; mensaje de datos, como el intercambio electrónico de datos, rastreo de información en la memoria y archivos de las computadoras o recuperación de datos "borrados" en el disco duro de las computadoras. 
No obstante, la Constitución Política, en su artículo $28^{13}$, de manera escalonada garantiza la legalidad de las actuaciones del Estado, ya que, en virtud de mandamiento escrito de autoridad judicial competente, con las formalidades legales y por motivo previamente definido en la ley, un individuo puede ser molestado en su persona o familia, o reducido a prisión o arresto, o detenido, pero solo se da esta situación cuando exista la formalidad judicial.

Ello implica que el juez (de garantías o de juzgamiento) debe examinar que los investigadores que realizaron el procedimiento - para este estudio se denomina "auditor forense"- lo hayan hecho con el respeto por los derechos fundamentales y con la observación de las formalidades de ley, previo a ser aceptado (art. 29); en caso contrario, la prueba será nula de pleno derecho, por lo que deberá excluirse de la actuación, salvo las excepciones de ley (Ley 906 de 2004, arts. 23, 360 y 455).

Por su parte, la Fiscalía General de la Nación expidió el Manual de procedimientos del sistema de cadena de custodia, en el que unificó los criterios frente al tema, los cuales también son aplicables a la defens $\mathrm{a}^{14}$, y precisó que la cadena de custodia es el conjunto de procedimientos que permiten asegurar las características originales de los elementos de prueba, desde su recolección hasta su disposición final cuando el juez lo autorice, con el fin de alcanzar niveles altos de convicción al momento de ser presentados y valorados.

La cadena de custodia es un sistema documentado, formado por una serie de instrucciones y registros, que se aplica a los elementos probatorios y a la evidencia

${ }^{13}$ Constitución Política de Colombia. Artículo 28. Toda persona es libre. Nadie puede ser molestado en su persona o familia, ni reducido a prisión o arresto, ni detenido, ni su domicilio registrado, sino en virtud de mandamiento escrito de autoridad judicial competente, con las formalidades legales y por motivo previamente definido en la ley. La persona detenida preventivamente será puesta a disposición del juez competente dentro de las treinta y seis (36) horas siguientes, para que este adopte la decisión correspondiente en el término que establezca la ley. En ningún caso podrá haber detención, prisión ni arresto por deudas, ni penas y medidas de seguridad imprescriptibles. Una ley estatutaria reglamentará la forma en que, sin previa orden judicial, las autoridades que ella señale puedan realizar detenciones, allanamientos y registros domiciliarios, con aviso inmediato a la Procuraduría General de la Nación y control judicial posterior dentro de las treinta y seis (36) horas siguientes, siempre que existan serios motivos para prevenir la comisión de actos terroristas. Al iniciar cada período de sesiones, el Gobierno rendirá informe al Congreso sobre el uso que se haya hecho de esta facultad. Los funcionarios que abusen de las medidas a que se refiere este artículo incurrirán en falta gravísima, sin perjuicio de las demás responsabilidades a que hubiere lugar.

14 Quien también podrá buscar, identificar empíricamente, recoger y embalar los elementos materiales probatorios y evidencia física, y solicitar sean examinados por el Instituto Nacional de Medicina Legal y Ciencias Forenses (268). 
física por parte de las personas responsables de su manejo, desde el momento en el que se encuentran o aportan a la investigación hasta su disposición final ${ }^{15}$.

De lo anterior se infiere que tanto el servidor público como el particular pueden pretender recolectar evidencia física con el fin de ser presentada para su contradicción, teniendo en cuenta los protocolos de la cadena de custodia previamente elaborados por el Estado para evitar la suplantación o alteración de los elementos - protocolos que son de riguroso cumplimiento- y levantar un acta que deberá estar suscrita por el funcionario y las personas que intervinieron en su realización.

Por lo anterior, el auditor forense deberá atender, desde el punto de vista procesal penal, la cadena de custodia, regulada en los artículos 67,68, 213, 216, 254, 255,258, 259, 260, 265, 276 y 277 de la Ley 906 de 2004, que aplica cuando se quiera demostrar la autenticidad de los elementos materiales probatorios y evidencia física, para lo cual se tendrán en cuenta aspectos relacionados con el elemento, como la identidad, el estado original, las condiciones de recolección, la preservación, el embalaje y envío, los lugares y fechas de permanencia y los cambios que cada custodio haya realizado. Y también se considerarán aspectos tendientes a la identificación de todas las personas que tuvieron contacto con esos elementos, quienes serán responsables por su recolección, preservación y entrega a la autoridad correspondiente ${ }^{16}$.

${ }^{15}$ Murillo (2007) expresa que la cadena de custodia permite no solo [...] garantizar su autenticidad, sino demostrar que se han aplicado procedimientos estandarizados para asegurar las condiciones de identidad, integridad, preservación, seguridad, continuidad y registro de estos [...] es la aplicación de una serie de normas tendientes a asegurar, embalar y proteger cada elemento material probatorio para evitar su destrucción, suplantación o contaminación, lo que podría implicar serios procesos en la investigación de una conducta punible

${ }^{16}$ En este orden de ideas, la cadena de custodia inicia cuando el investigador traslada el elemento al laboratorio correspondiente y lo entrega al perito técnico científico que corresponda según la especialidad, quien dejará constancia del estado en que se encuentra y procederá al análisis, y su informe será remitido con posterioridad al fiscal con la certificación de que en todo momento estuvo custodiado, y termina cuando el juez así lo disponga. 
Figura1. Procedimiento para la cadena de custodia

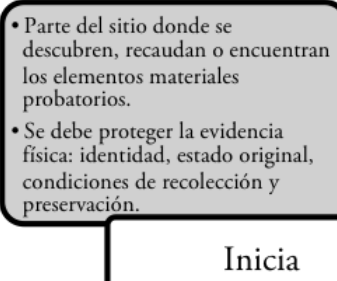

En el caso del derecho penal, el funcionario judicial mostrará su evidencia sobre los hechos de discusión, que serán refutados por el instructor, operador judicial y sujetos procesales, según el caso estudiado (Cano, D., Lugo, D., Cano, M., \& Cano, J, 2008); en particular, el auditor forense, por medio de la prueba penal y atendiendo al procedimiento para la cadena de custodia, dará instrumentos de mucho valor que contengan elementos de juicio suficientes para que el juez decida sobre el hecho objeto de investigación ${ }^{17}$.

\subsection{La cadena de custodia para la auditoría forense}

Dentro de las fases propias de la auditoría forense (planeación, ejecución e informe), el auditor tendrá en cuenta la cadena de custodia para que la prueba que ha obtenido, contemple los aspectos legales para que sirva de evidencia, dentro del proceso. El trabajo de auditoría se debe caracterizar, principalmente, por la comunicación eficiente con quien tenga interés en conocer sobre el asunto objeto de estudio y con todos los que estén implicados en el conocimiento de la situación

${ }^{17}$ Cano, D., Lugo, D., Cano, M., \& Cano, J. E. (2008) argumentan que, en el caso del derecho penal, el funcionario judicial mostrará su evidencia sobre los hechos de discusión, que serán refutados por el instructor, operador judicial y sujetos procesales, de acuerdo con el caso estudiado. 
auditada, para formarse un conocimiento amplio con el que se pueda realizar síntesis desde los múltiples saberes científicos y técnicos que convergen en las organizaciones (Montilla y Herrera, 2006).

Por otra parte, la auditoría forense está ligada a la detección de errores y fraudes en los estados financieros contables y los soportes que son la base para el registro contable. La inspección detallada se realiza sin dejar de lado la norma jurídica y las normas propias de la auditoría (NAI-NIA), legislación que en todas las fases mencionadas es de cabal cumplimiento, puesto que "la razón de ser de la auditoría es la de proteger la posesión y buen devenir económico del ente a favor de sus interesados (propietarios-sociedad), satisfaciendo la necesidad de certeza requerida por los usuarios de la información contable" (Montilla y Herrera, 2006).

La cadena de custodia implica, necesariamente los siguientes factores: identidad, estado original, condiciones de recolección, preservación, embalaje y envío; lugares y fechas de permanencia y los cambios que cada custodio haya realizado. Igualmente se registrará el nombre y la identificación de todas las personas que hayan estado en contacto con esos elementos (art. 254 de la Ley 906 de 2004).

La cadena de custodia se iniciará en el lugar donde se descubran, recauden o encuentren los elementos materiales probatorios y evidencia física, y finaliza por orden de autoridad competente.

A continuación, se explican de manera gráfica las fases de la auditoría, su debido proceso y la cadena de custodia: 
Figura 2. Fase de la planeación

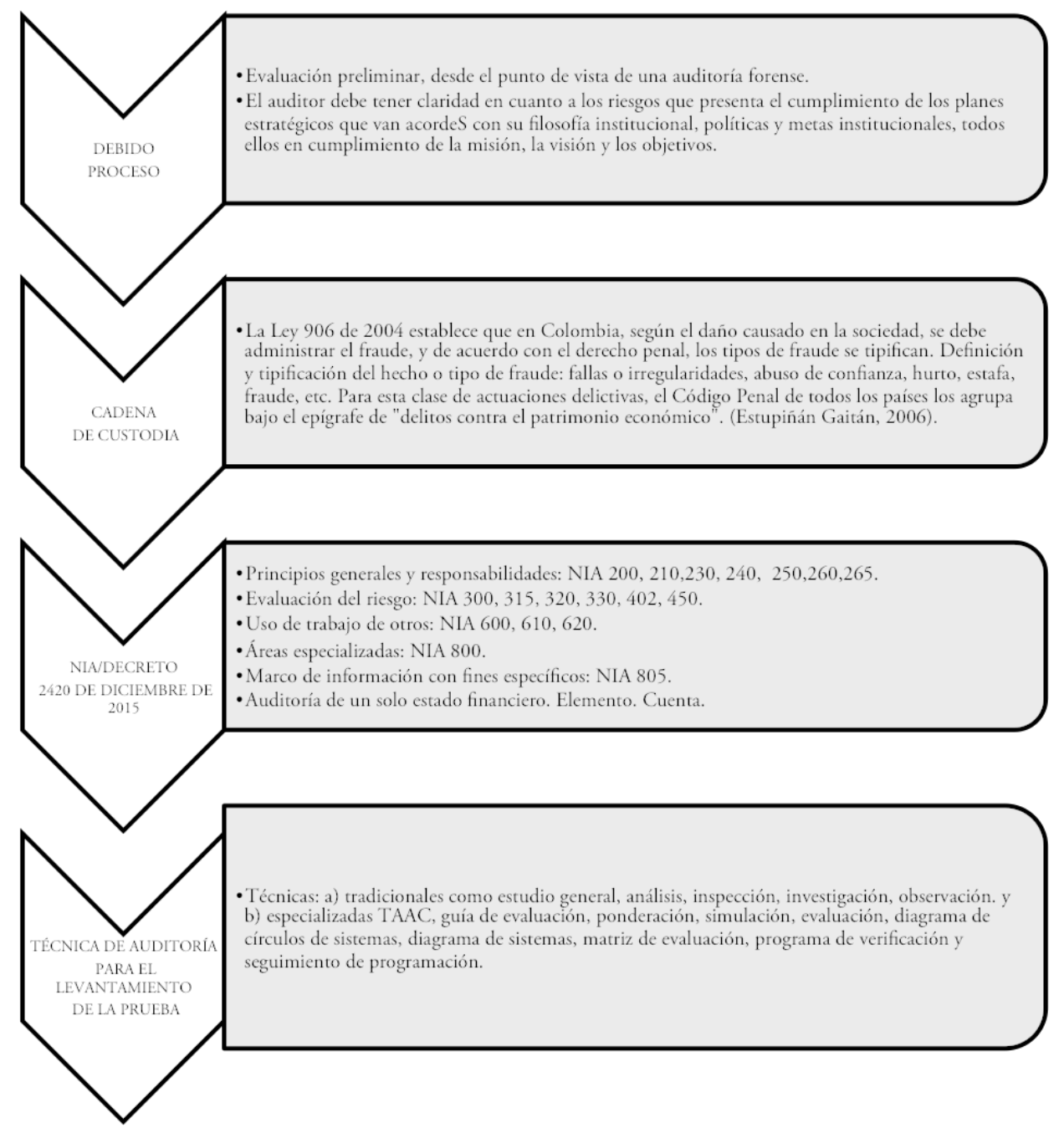

Fuente: Cano, D., Lugo, D., Cano, M., \& Cano, J. E. (2008) y Estupiñán (2006). Adaptado y modificado por los autores. 
Figura 3. Fase 2: recopilación de evidencias

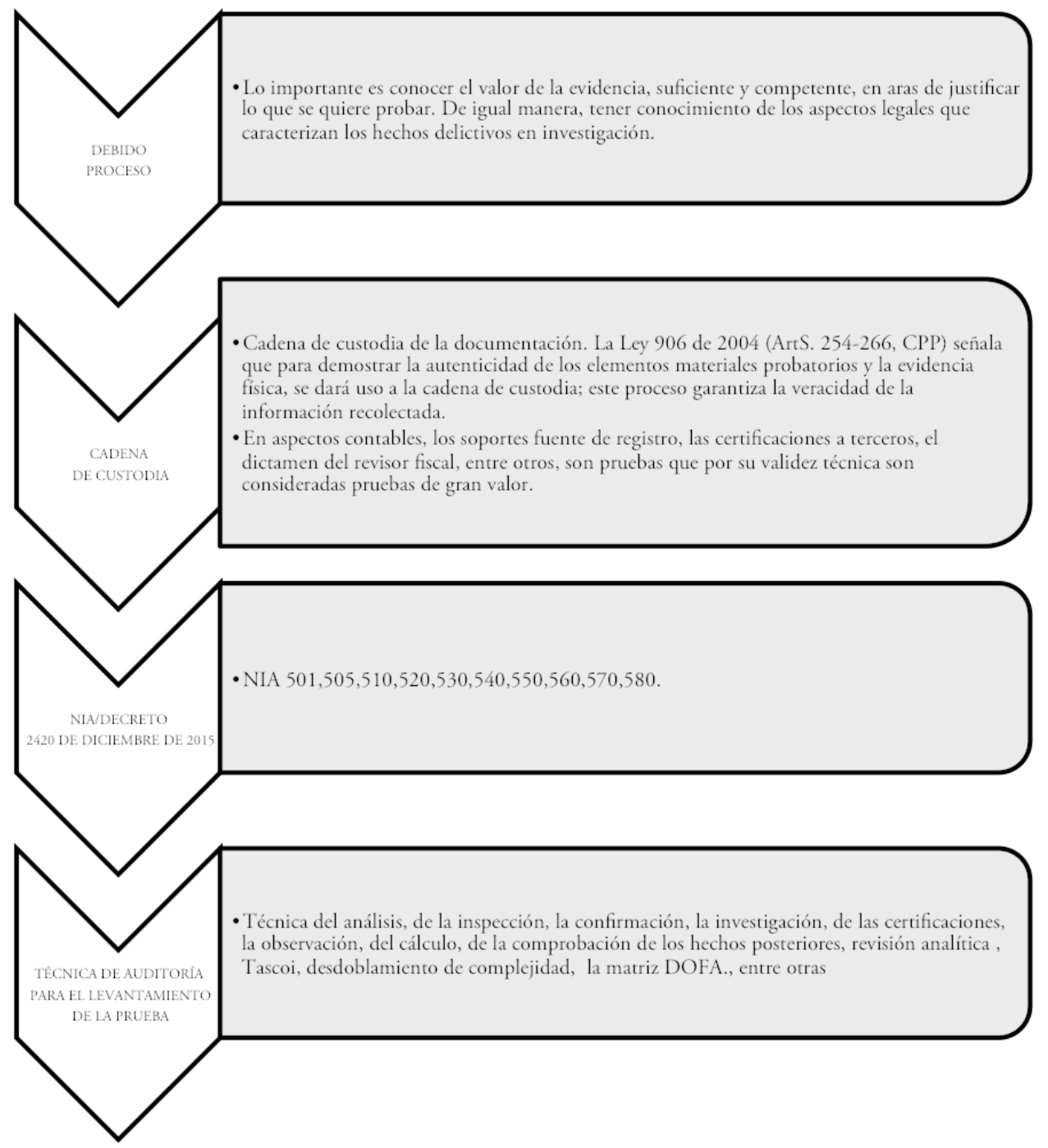

Fuente: Cano, D., Lugo, D., Cano, M., \& Cano, J. E. (2008) y Estupiñán (2006). Adaptado y modificado por los autores. 
Figura 4. Informe de auditoria

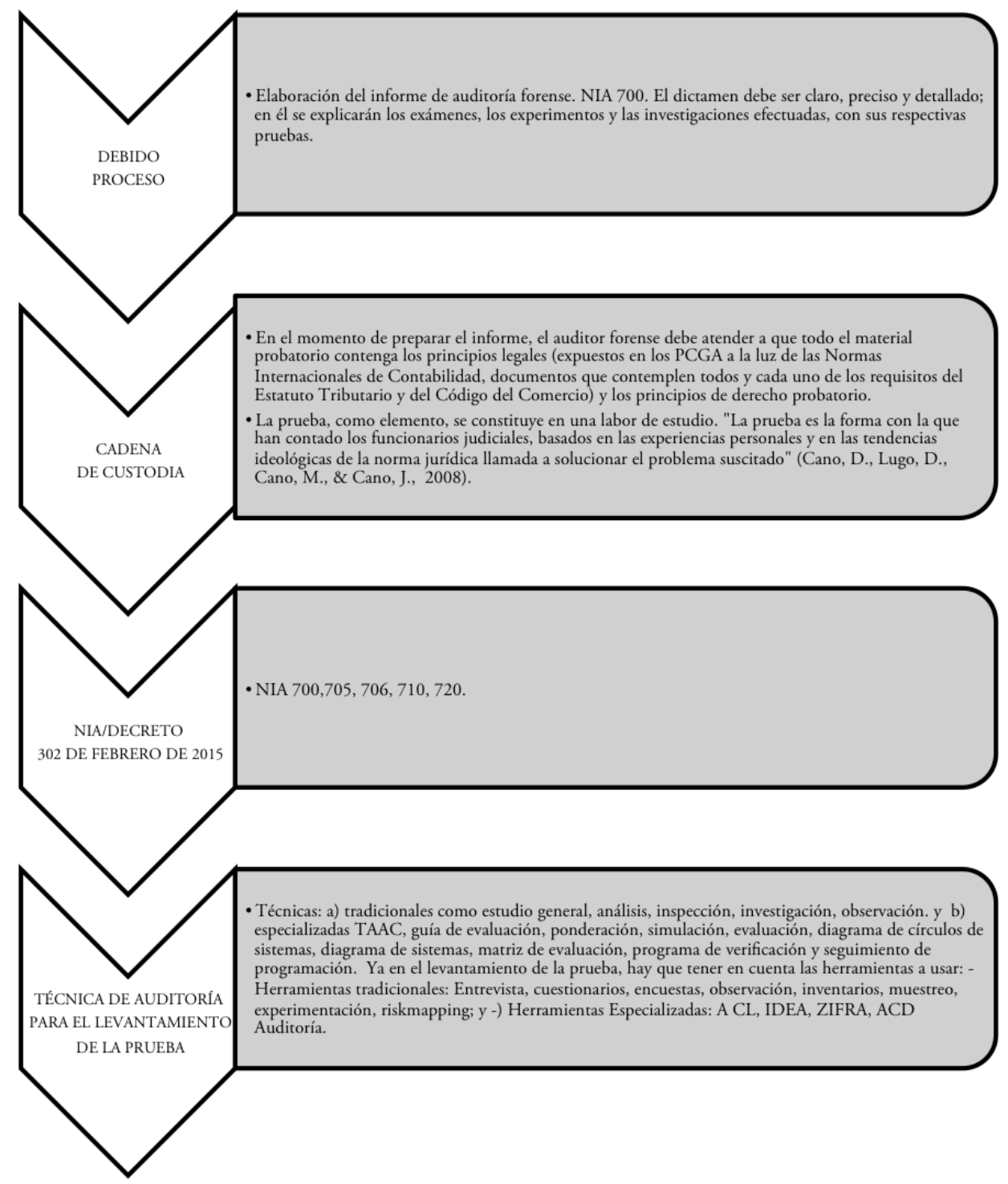

Fuente: Cano, D., Lugo, D., Cano, M., \& Cano, J. E. (2008) y Estupiñán (2006). Adaptado y modificado por los autores. 


\subsection{Pruebas judiciales presentadas por el auditor forense}

Para realizar un debido proceso en la cadena de custodia, se debe tener en cuenta la responsabilidad, la seguridad y la preservación de cada una de las evidencias físicas halladas por el auditor forense, de manera que se garanticen su autenticidad y veracidad.

El auditor forense, como experto contable, deberá presentar sus evidencias ante el jurado y acudir al juez para que pueda fallar, ya que tiene a la mano las pruebas judiciales para que se demuestre la realidad de los hechos controversiales ${ }^{18}$, y para ello algunos soportes o pruebas físicas que deben presentarse en el proceso son los siguientes: comprobantes de egreso, a los que se adjuntan las facturas o los documentos equivalentes a las facturas con los requisitos de ley ${ }^{19}$; su inspección por parte del auditor para poder dar a conocer situaciones anómalas, como devoluciones fraudulentas de impuestos, que caen, sin lugar a dudas, en la figura delictiva que contempla la Ley 906 del Código de Procedimiento Penal.

Por otra parte, los documentos internos y externos, como los libros contables probatorios, acatarán las disposiciones del artículo 15 de la Constitución Política de Colombia, Código de Comercio (Decreto 410 de 1971), Código de Procedimiento Civil (Decreto 1400 de 1970), Estatuto Tributario (Decreto 624 de 1989) y Decretos Reglamentarios, en cuanto a su aspecto técnico, contemplados en las Normas Internacionales de Información Financiera (NIIF y NIC) y las Normas Internacionales de Contabilidad, que iniciaron su proceso con la Ley 1314 de 2009 y que se compilaron en el Decreto reglamentario 2420 de diciembre de 2015.

El auditor forense deberá tener en cuenta aquellos libros de contabilidad obligatorios y auxiliares como punto de análisis de los registros contables, junto con

${ }^{18}$ Soba Bracesco (2014) expone que no hay que olvidar que la función de la prueba pericial es ofrecer al juez la información técnica y científica para juzgar, nunca sustituirlo en la decisión.

${ }^{19}$ El Estatuto Tributario, en su artículo art. 617 contempla: Requisitos de la factura de venta. Para efectos tributarios, la expedición de factura a que se refiere el artículo 615 consiste en entregar el original de esta, con el lleno de los siguientes requisitos: a) estar denominada expresamente como factura de venta; b) apellidos y nombre o razón y NIT del vendedor o de quien presta el servicio; c) apellidos y nombre o razón social y NIT del adquirente de los bienes o servicios, junto con la discriminación del IVA pagado; d) llevar un número que corresponda a un sistema de numeración consecutiva de facturas de venta; e) fecha de su expedición; f) descripción específica o genérica de los artículos vendidos o de los servicios prestados; g) valor total de la operación; h) nombre o razón social y NIT del impresor de la factura; i) indicar la calidad de retenedor del impuesto sobre las ventas. 
sus documentos de soporte ${ }^{20}$, que, en ocasiones, representan los papeles de trabajo del auditor ${ }^{21}$. A nivel externo, la circularización, la confirmación, la certificación, la conciliación, entre otras técnicas de auditoría, soportan los hechos económicos registrados y sirven de evidencia para presentarse ante el juez.

En conclusión, el auditor forense es libre de practicar las pruebas necesarias que sustenten el proceso judicial, atendiendo al debido proceso y a los hechos controversiales, pruebas que son obtenidas conforme a las técnicas y herramientas de auditoría -tradicionales o especializadas - contemplados en las Normas Internacionales de Auditoría (NIA) y en el Decreto 0302 de febrero de $2015^{22}$.

\section{Conclusiones}

La auditoría forense es el proceso mediante el cual un auditor forense -delegado específicamente por el juez- recopila prueba amplia y suficiente de cara a las necesidades de los diferentes stakeholders, conforme a las Normas Internacionales de Auditoría, al Decreto 2420 de diciembre de 2015 y al Código de Procedimiento Penal, apoyado en instrumentos tradicionales y especializados, y que tiene como fin que la prueba sea fidedigna y confiable para que pueda ser usada ante los tribunales y se le dé la categoría de prueba pericial.

A partir del año 2004, la Fiscalía General de la Nación -como órgano rector en los procesos de fiscalización- ha enfatizado en el grado de importancia que debe brindarse al manejo a las pruebas recolectadas por el auditor en el proceso de investigación de una auditoría (cadena de custodia). Por tal motivo, el auditor -en este caso, el auditor forense- debe tener un amplio conocimiento de las diferentes maneras que existen para cometer delitos económicos o financieros que pueden suceder en el ejercicio de la actividad económica de las organizaciones. Por lo anterior, las pruebas periciales deben cumplir los requerimientos establecidos por la

${ }^{20}$ Leal, Rodríguez y González (2010) exponen que "los contadores públicos, cuando se desempeñan en lo forense, deben tener en cuenta que los documentos pueden existir jurídicamente y ser válidos en sí mismos y como prueba en determinado proceso, pero carecer de eficacia probatoria, y para esto se requiere cumplir con los requisitos establecidos en el Sistema Penal Acusatorio”.

${ }^{21}$ NIA 230 Documentación de trabajo (papeles de trabajo).

${ }^{22}$ Los instrumentos de auditoría representan hoy en día la ayuda necesaria para el auditor debido a que los actuales cambios en el tratamiento de la información contable le exigen estar acorde con la evolución de las tecnologías de información y comunicación; por ello, el tratamiento de la información contable cada día se hace sobre plataformas tecnológicas diferentes, las cuales el auditor forense deberá administrar con software especializado para el análisis de la información. 
ley, para lo cual el auditor forense debe aplicar diferentes técnicas, procedimientos e instrumentos que propendan hacia la legalidad de la prueba.

A partir de los diferentes tipos de fraudes que se pueden presentar en el interior de una entidad, como pueden ser la omisión de documentos, la manipulación de contratos, el lavado de dinero, el maquillaje de los estados financieros y personas ficticias, se hace necesario que en la cadena de custodia se establezcan la identidad, la preservación, la seguridad y el almacenamiento de las evidencias físicas o de los elementos materiales probatorios encontrados por el auditor.

\section{Referencias}

Campo, Á. L. (2011). La prueba pericial en los procesos judiciales. Recuperado de goo.g1/3yO220 Cano, D., Lugo, D., Cano, M., \& Cano, J. E. (2008). Auditoría financiera forense en la investigación de delitos económicos y financieros, lavado de dinero y activos, y financiación del terrorismo. Bogotá: ECOE Ediciones.

Caro Espitia, N. R., Hernández Aros, L., Gallego Cossio, L. C., Guzmán, F., \& Heimer, M. (2015). El dictamen pericial contable, medio de prueba y criterios de valoración. Dialogos de Saberes, (42).

Cortés, S. (2011). La constitucionalización del derecho y la interpretación

jurídica constitucional. Revista Virtual Via Inveniendi et Iudicandi, 6(2). Recuperado de goo.gl/kQwR2q

Estupiñán Gaitán, R. (2006). Control interno y fraude con base en los ciclos transaccionales (3. ${ }^{\circledR}$ ed.). Bogotá: ECOE Ediciones.

Fiscalía General de la Nación. (2012). Manual de procedimientos para cadena de custodia. Bogotá: Autor. Recuperado de http://www.fiscalia.gov.co/en/wp-content/uploads/2012/01/ manualcadena2.pdf

Leal, L., Rodríguez, E. y González, R. (2010). Auditoría forense: los procedimientos del contador público en la investigación del fraude corporativo. Gestión E Sociedad, 3(2), 141-160. Recuperado de goo.g1/yQR4lk

Lluch, X. A. (2012). Derecho probatorio. España: J. M. Bosch Editor. http://site.ebrary. com/lib/ucooperativasp/Doc?id=10664709\&ppg=19.

Montilla, Ó. y Herrera, L. G. (2006). El deber ser de la auditoría. Estudios Gerenciales, 98, 83-110. Recuperado de goo.g1/dpTDBT

Murillo, H., Parra, D. y Espitia, S. (2007). Cadena de custodia, su trasendencia y aplicacion en el sistema penal acusatorio durante 2005-2006. Manizales: Universidad de Manizales. 
Ramírez, M. y Reina, J. (2013). Metodología y desarrollo de la auditoría forense en la detección del fraude. Cuadernos de Administración, 29(50), 186-195. Recuperado de goo.g1/LspGU3

Rodríguez, B. (2009) Una aproximación a la auditoría forense. Cuadernos de Contabilidad, 3(17), 233-269.

Soba Bracesco, I. M. (2014). La incursión en el conocimiento científico a través de la prueba pericial: su impacto en la decisión judicial. Revista del Instituto Colombiano de Derecho Procesal, 40, 227-261. Recuperado de goo.g1/D0pZqM

Singleton, A. J., Bologna, G. J. y Lindquist, R. J. (2006). Fraud auditing and forensic accounting (3. ${ }^{a}$ ed.). Hoboken, U. S. A.: Wiley.

\section{Leyes decretos y otros documentos oficiales}

Asamblea Nacional Constituyente. (1991). Constitución Politica de Colombia. Bogotá: Legis. Congreso de la República de Colombia. (30 de diciembre de 1960). Ley 145 de 1960. Por la cual se reglamenta el ejercicio de la profesión de contador público. Diario Oficial 30433 del 3 de febrero de 1961. Recuperado de goo.gl/jNWuDI

. (13 de diciembre de 1990). Ley 43 de 1990. Por la cual se adiciona la Ley 145 de 1960, reglamentaria de la profesión de contador público, y se dictan otras disposiciones. Diario Oficial 39602 del 13 de diciembre de 1990. Recuperado de goo.gl/iN0RRE . (31 de agosto de 2004). Ley 906 de 2004. Por la cual se expide el Código de Procedimiento Penal. (Corregida de conformidad con el Decreto 2770 de 2004). Diario Oficial 45658 del $1 .^{\circ}$ septiembre de 2004. Recuperado de goo.g1/ZPPkbx . (13 de julio de 2009). Ley 1314 de 2009. Por la cual se regulan los principios y normas de contabilidad e información financiera y de aseguramiento de información aceptados en Colombia, se señalan las autoridades competentes, el procedimiento para su expedición y se determinan las entidades responsables de vigilar su cumplimiento. Diario Oficial 47.409 del 13 julio de 2009. Recuperado de goo.g1/9LRRHS

. (12 de julio de 2012). Ley 1564 de 2012. Por medio de la cual se expide el Código General del Proceso y se dictan otras disposiciones. Diario Oficial 48489 del 12 julio de 2012. Recuperado de goo.g1/kXpwJd

Corte Constitucional. (2000). Sentencia C-530 de 2000. Recuperada de goo.g1/NE0PBN

OEA. (1969). Convención Americana sobre Derechos Humanos. Suscrita en la Conferencia Especializada Interamericana sobre Derechos Humanos, San José, Costa Rica. Recuperado de goo.gl/12FKBc 
ONU. (16 de diciembre de 1996). Pacto Internacional de Derechos Civiles y Politicos. Recuperado de goo.g1/p54um 9

Presidencia de la República de Colombia. (6 de agosto de 1970). Decreto 1400 de 1970. Por el cual se expide el Código de Procedimiento Civil. Diario Oficial 33150 del 21 de septiembre de 1970. Recuperado de goo.g1/bTC9pi

. (27 de marzo de 1971). Decreto 410 de 1971. Por el cual se expide el Código de Comercio. Diario Oficial 33.339 del 16 de junio de 1971. Recuperado de goo.g1/LsXBMi (30 de marzo de 1989). Decreto 624 de 1989. Por el cual se expide el Estatuto Tributario de los impuestos administrados por la Dirección General de Impuesto Nacionales. Diario Oficial 38756 del 30 de marzo de 1989. Recuperado de goo.g1/IUihtd (14 de Diciembre de 2015). Decreto 2420 de 2015. Por medio del cual se expide el Decreto Único Reglamentario de las Normas de Contabilidad, de Información Financiera y de Aseguramiento de la Información y se dictan otras disposiciones”. Diario Oficial No. 49.726 de 14 de diciembre de 2015. Recuperado de https://www.cancilleria. gov.co/sites/default/files/Normograma/docs/decreto_2420_2015.htm

(20 de febrero de 2015). Decreto 0302 de 2015. Por el cual se reglamenta la Ley 1314 de 2009 sobre el marco técnico normativo para las normas de aseguramiento de la información. Diario Oficial 49431 del 20 de febrero de 2015. Recuperado de goo. g1/0HWMHa 